\title{
Evaluation of robotic cardiac surgery simulation training: A randomized controlled trial
}

\author{
Matthew Valdis, MD, ${ }^{\mathrm{a}}$ Michael W. A. Chu, MD, ${ }^{\mathrm{a}}$ Christopher Schlachta, MD, ${ }^{\mathrm{b}}$ and Bob Kiaii, $\mathrm{MD}^{\mathrm{a}}$
}

\section{ABSTRACT}

Objective: To compare the currently available simulation training modalities used to teach robotic surgery.

Methods: Forty surgical trainees completed a standardized robotic 10-cm dissection of the internal thoracic artery and placed 3 sutures of a mitral valve annuloplasty in porcine models and were then randomized to a wet lab, a dry lab, a virtual reality lab, or a control group that received no additional training. All groups trained to a level of proficiency determined by 2 expert robotic cardiac surgeons. All assessments were evaluated using the Global Evaluative Assessment of Robotic Skills in a blinded fashion.

Results: Wet lab trainees showed the greatest improvement in time-based scoring and the objective scoring tool compared with the experts (mean, $24.9 \pm 1.7 \mathrm{vs}$ $24.9 \pm 2.6 ; P=.704)$. The virtual reality lab improved their scores and met the level of proficiency set by our experts for all primary outcomes (mean, $24.9 \pm 1.7$ vs $22.8 \pm 3.7 ; P=.103$ ). Only the control group trainees were not able to meet the expert level of proficiency for both time-based scores and the objective scoring tool (mean, $24.9 \pm 1.7$ vs $11.0 \pm 4.5 ; P<.001$ ). The average duration of training was shortest for the dry lab and longest for the virtual reality simulation ( 1.6 hours vs 9.3 hours; $P<.001)$.

Conclusions: We have completed the first randomized controlled trial to objectively compare the different training modalities of robotic surgery. Our data demonstrate the significant benefits of wet lab and virtual reality robotic simulation training and highlight key differences in current training methods. This study can help guide training programs in investing resources in cost-effective, high-yield simulation exercises. (J Thorac Cardiovasc Surg 2016;151:1498-505)

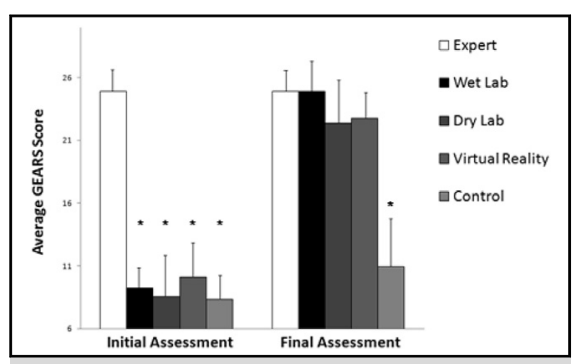

Relative acquisition of robotic skills with different simulation training modalities.

\section{Central Message}

Wet lab simulation provides the most efficient training for robotic surgery to obtain expert level skill in a reasonable time frame.

\section{Perspective}

Exposure to robotic surgery and the development of robotic skill is difficult to obtain with current training methods. Simulation allows for skill development outside of the operating room. There is no previously published comparison of different simulation modalities in use today. This work highlights the benefits of different simulation modalities and will guide training programs in providing the most efficient training.

See Editorial Commentary page 1506.
Since its inception in the late 1990s, robotic cardiac surgery has increased in popularity, with large numbers of cases now performed at specialized centers. ${ }^{1-3}$ This increase has been driven by patient demands for less-invasive approaches to sternotomy. ${ }^{4-6}$ But despite the demonstrated benefits and the increasing number of robotic surgery cases, the exposure to

From the Divisions of a Cardiac Surgery and ${ }^{\mathrm{b}}$ General Surgery, Department of Surgery, Western University, London Health Sciences Centre, London, Ontario, Canada.

Funding for this research was provided in part by a resident research grant from St. Jude Medical.

Registered at ClincalTrials.gov (NCT 02357056).

Received for publication July 15, 2015; revisions received Oct 17, 2015; accepted for publication Feb 7, 2016; available ahead of print March 8, 2016.

Address for reprints: Matthew Valdis, MD, Department of Cardiac Surgery, B6 University Hospital, London Health Sciences Centre, 339 Windermere Rd, London, Ontario, Canada N6A 5A5 (E-mail: matthew.valdis@gmail.com).

$0022-5223 / \$ 36.00$

Copyright (c) 2016 by The American Association for Thoracic Surgery

http://dx.doi.org/10.1016/j.jtcvs.2016.02.016 robotic surgery remains very limited for surgical trainees., At present, no credentialing body requires proficiency in robotic surgery for the successful completion of any residency program. ${ }^{7-9}$ This factor, along with the high up-front costs, operating room time constraints, and administrative demands for improved outcomes, all contribute to the limited exposure of surgical trainees.

Schachner et $\mathrm{al}^{10}$ reported the experience of junior trainees as they progressed to senior roles in a robotic cardiac surgery program and tracked their intraoperative performance compared with senior surgeons. The authors

Scanning this QR code will take you to the appendices for this article. 


\section{Abbreviations and Acronyms \\ FLS = Fundamentals of Laparoscopic Surgery \\ GEARS $=$ Global Evaluative Assessment of Robotic Skills \\ ITA $=$ internal thoracic artery}

concluded that robotic cardiac surgery can be taught through a stepwise approach, with portions of the operation entrusted to trainees, with responsibilities increasing as their surgical skills improve. ${ }^{10}$ This method of training represents the classic model of education and skill acquisition in surgery; however, it is inefficient, and does not make use of new training modalities in surgical disciplines, such as simulation.

A 2011 systematic review of 35 simulation studies (10 wet lab, 12 dry lab, and 13 virtual reality, with the number of subjects ranging from 2 to 49), identified the need for a competency-based training system and a stepwise approach with objective assessments in robotic surgery. ${ }^{11}$ Only 3 of those studies involved any comparison between different training modalities, and all 3 had a sample size of only 2 participants per group. ${ }^{11}$

Simulation offers great benefits to surgical trainees by allowing for repeated practice of a specific skill set in a controlled and safe environment. ${ }^{12-15}$ This style of training, vastly different from historical surgical training, is necessitated by the ever-increasing focus on outcomebased initiatives, combined with aging and frailer patients and the public's demand for a less-invasive surgical approach.

The 3 main areas of simulated surgical training currently in use are cadaveric and animal models (wet labs), dry labs, and virtual reality simulation. ${ }^{16-20}$ Despite their ongoing use, no direct comparison of these methods exists within the current literature. ${ }^{9}$ We designed the present study to determine the most effective method for robotic cardiac surgery training through a prospective randomized controlled trial comparing wet lab, dry lab, and virtual reality simulations with an untrained control group. For this we used a time-based scoring system adapted from the Fundamentals of Laparoscopic Surgery (FLS) program ${ }^{21}$ and the Global Evaluative Assessment of Robotic Skill (GEARS) scoring tool, a validated objective method for scoring intraoperative robotic performance (Appendix 4). ${ }^{22}$ This work represents one of the largest trials of its kind and the first-ever randomized controlled trial comparing the currently available training modalities in robotic surgery.

\section{MATERIALS AND METHODS}

This study was approved by Western University's Health Science Research Ethics Board, and has been registered into the public domain at ClinicalTrials.gov (NCT 02357056).

\section{Participant Selection, Initial Assessment, and Randomization}

Forty surgical trainees each with less than 10 hours of experience with the da Vinci Surgical System (Intuitive Surgical, Sunnyvale, Calif) or any robotic surgical simulator were enrolled in the study. Each trainee was shown 5-minute videos of a robotically harvested internal thoracic artery (ITA) and a robotic-assisted mitral valve annuloplasty, highlighting basic operative techniques and relevant anatomy. The trainee was then required to harvest a 10 -cm-long segment of the ITA pedicle off a porcine chest wall using robotic Debakey forceps and monopolar spatula cautery.

Next, using a porcine heart model of the mitral valve, two 3-0 Ethibond Excel sutures (Ethicon, Cincinnati, Ohio) were passed to the trainee by an assistant and placed through both the posteromedial and anterolateral trigones of the mitral valve. A third suture was given to the trainee and placed through the annulus of the mitral valve and then through a flexible annuloplasty band (St. Jude Medical, St. Paul, Minn). Both of these tasks were timed and recorded on the robot's camera using a Stryker 1288 HD Camera Control Unit (Stryker, Kalamazoo, Mich), and coded for blinded assessment.

After completing the initial assessment, the trainees were randomized to 1 of 4 different robotic training streams - wet lab, dry lab, virtual reality simulation, or a control group-using concealed identical cards chosen from an opaque container (Figure 1).

\section{Wet Lab}

The wet lab consisted of the same 2 tasks of the initial assessment, with ongoing guidance and feedback provided by one of the study investigators. The level of proficiency for these tasks was set by the mean time of completion by 2 fellowship-trained expert robotic cardiac surgeons, who performed the robotic ITA harvest and mitral annuloplasty tasks 5 times each (Figure 2). To ensure that the achievement of proficiency was not a random occurrence, each trainee was required to pass each task 2 consecutive times based on time-based scores determined by an equation derived from the FLS scoring system (Appendix 2).

\section{Dry Lab}

The dry lab training stream consisted of 3 tasks to address camera movement and clutching, transferring and Endowrist manipulation, and needle control, needle driving, suturing, and intracorporeal knot tying. The first task used a predrawn template with 10 numbered boxes of varying shapes and sizes, each of which was surrounded by a dot on all 4 sides. Each participant was required to clutch and move the camera to focus on each box such that all 4 corners could be seen and all 4 surrounding dots were excluded (Appendix 1). The second and third tasks of the dry lab used the peg transfer and intracorporeal knot tying materials from tasks 1 and 5 of the standard FLS skills program. ${ }^{21}$ The methods for these tasks were exactly as specified by the FLS manual skills program, with laparoscopic instruments replaced with the da Vinci robot (Appendix 2). Levels of proficiency for each exercise were set by the mean scores of our 2 expert robotic cardiac surgeons completing each exercise 5 times.

\section{Virtual Reality}

We established a virtual reality training protocol specific to robotic cardiac surgery using the da Vinci Skills Simulator (Intuitive Surgical), a commercially available robotic surgical simulation platform. We surveyed our expert robotic cardiac surgeons to define skills important for robotic cardiac surgery. From this, we generated a list of useful virtual reality simulation exercises and created a 9-exercise curriculum specific to the skills required for robotic cardiac surgery (Appendix 3). Levels of proficiency for each task were set by allowing our expert surgeons to complete each exercise as many times as necessary until they felt that they had performed to a level indicative of their ability. From this, a level 


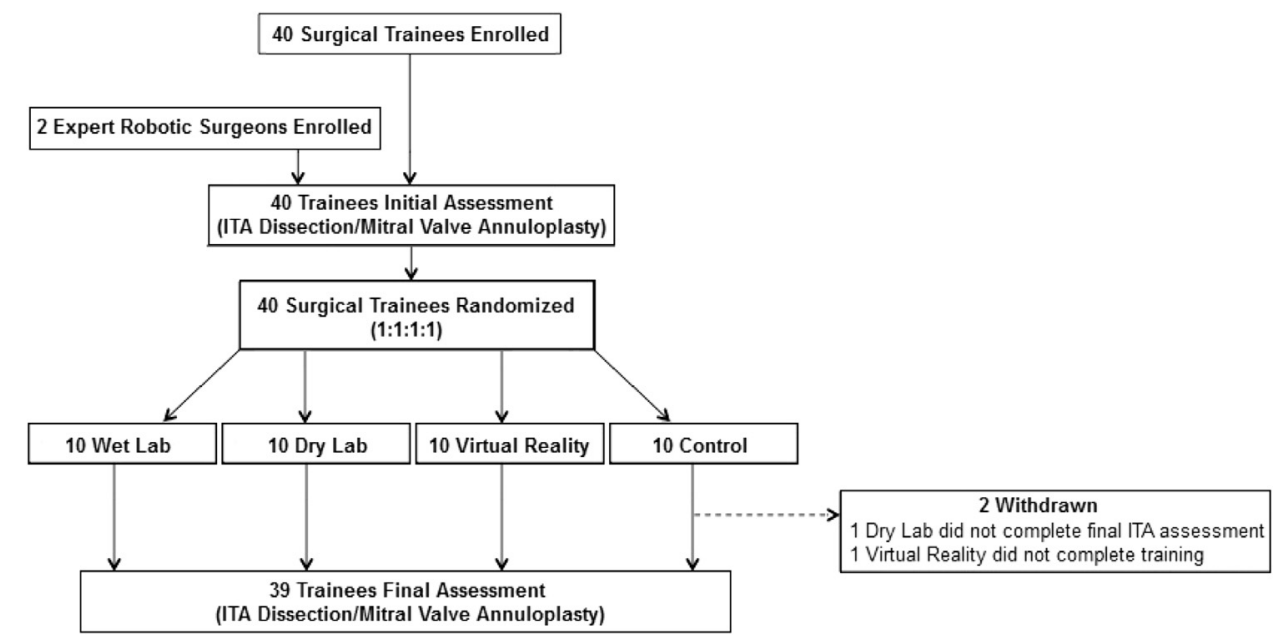

FIGURE 1. Allocation of treatment arm flow chart. ITA, Internal thoracic artery.

of proficiency for each task of $90 \%$ or greater with no critical errors was required to match the performance of our experts.

\section{Control}

A control group was used to assess for skill improvement from the initial assessment due to reasons other than the training that the other groups received. Trainees randomized to this group after the first assessment received no additional training on the robot.

\section{Primary Outcomes and Evaluation}

The primary outcomes for this study were the time-based scores on successful completion of the assessments and the mean GEARS score for each trainee's completion of the 2 assessment tasks. Each participant was allowed to repeat each exercise in the respective training stream up to 80 times to reach the level of proficiency set by our experts for that specific task. To ensure the successful completion of the exercise was not a random occurrence, each participant was required to pass each exercise 2 consecutive times, similar to the FLS training program.

On achieving the predetermined proficiency score for each task in their respective training stream, each participant was brought back and retested on the original robotic ITA harvest and mitral annuloplasty tasks. All attempts were timed and recorded. The deidentified recordings of the initial and final assessments were assessed objectively for intraoperative surgical skills using the GEARS assessment tool in a blinded fashion by a single investigator, to control for interobserver variability.

\section{Statistical Analysis}

Because no previous or similar study exists, we were unable to predict the standard error and significance of our primary outcomes before participant enrollment. Data recorded from 1 expert robotic surgeon and
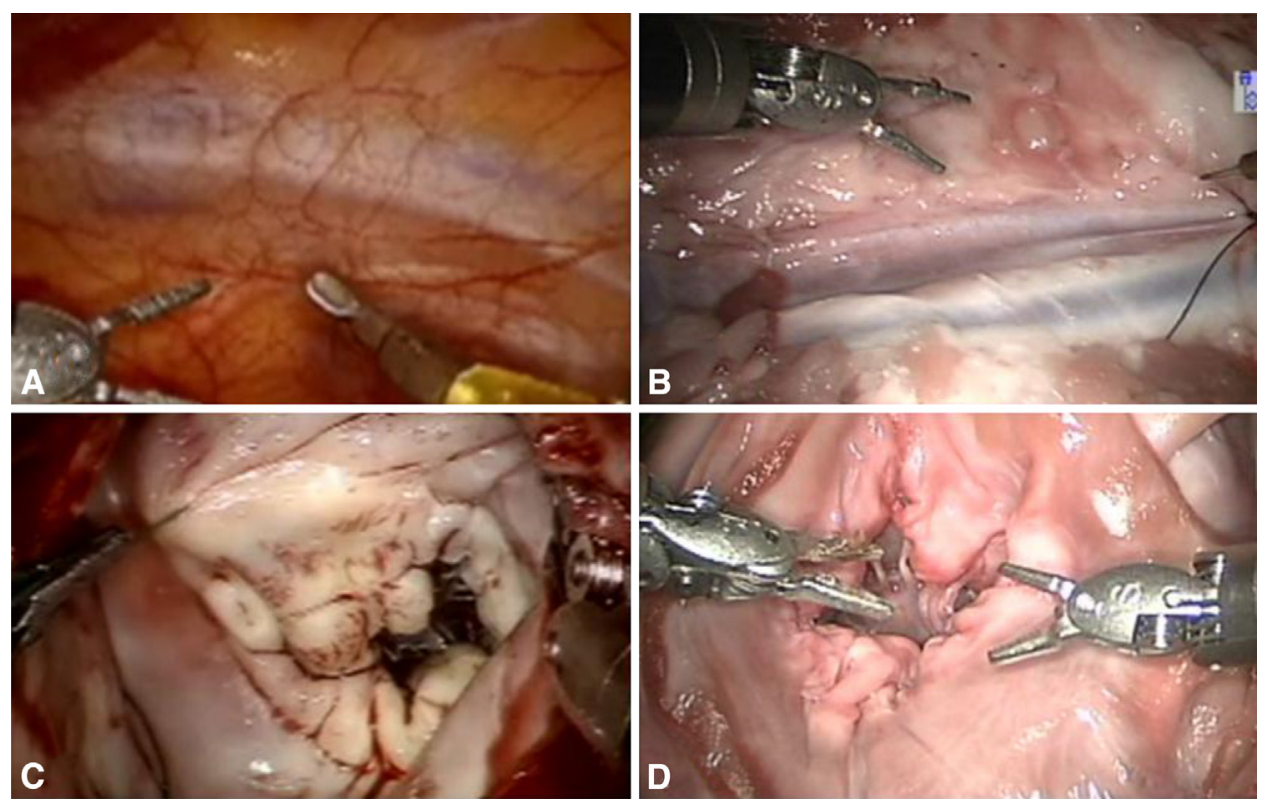

FIGURE 2. Wet lab simulation tasks. Comparison of intraoperative image from surgeon's console for ITA dissection in (A) compared with porcine model (B) and comparison of intraoperative image of mitral annuloplasty (C) with porcine model in the laboratory (D) shows the high degree of fidelity with wet lab simulation compared to actually robotic operating room experience. 
TABLE 1. Baseline demographic characteristics of study participants

\begin{tabular}{|c|c|c|c|c|c|}
\hline Characteristic & $\begin{array}{r}\text { Wet lab } \\
(n=10)\end{array}$ & $\begin{array}{c}\text { Dry lab } \\
(\mathrm{n}=10)\end{array}$ & Virtual reality $(n=10)$ & $\begin{array}{r}\text { Control } \\
(\mathbf{n}=\mathbf{1 0})\end{array}$ & $P$ value \\
\hline Age, yr, mean $\pm \mathrm{SD}$ & $31.3 \pm 4.0$ & $32.3 \pm 5.8$ & $32.7 \pm 6.1$ & $29.9 \pm 2.4$ & .579 \\
\hline \multicolumn{6}{|l|}{ Sex, $n(\%)$} \\
\hline Male & $8(80.0)$ & $6(60.0)$ & $8(80.0)$ & $6(60.0)$ & .619 \\
\hline Female & $2(20.0)$ & $4(40.0)$ & $2(20.0)$ & $4(40.0)$ & \\
\hline Year of training, mean $\pm \mathrm{SD}$ & $5 \pm 2.5$ & $5 \pm 2.9$ & $5 \pm 3.0$ & $4 \pm 2.4$ & .801 \\
\hline Previous robotic experience, $\mathrm{h}$, mean $\pm \mathrm{SD}$ & $1.7 \pm 3.9$ & $0.3 \pm 0.7$ & $2.6 \pm 3.2$ & $0.8 \pm 2.5$ & .305 \\
\hline $10 \mathrm{~cm}$ ITA dissection score, mean $\pm \mathrm{SD}$ & $488.8 \pm 228.6$ & $388.9 \pm 295.1$ & $457.6 \pm 259.9$ & $451.0 \pm 264.1$ & .859 \\
\hline ITA GEARS score, mean \pm SD & $10.3 \pm 2.4$ & $9.4 \pm 3.4$ & $12.5 \pm 5.1$ & $9.2 \pm 3.0$ & .942 \\
\hline Annuloplasty score, mean \pm SD & $381.1 \pm 107.8$ & $304.9 \pm 197.0$ & $409.5 \pm 106.1$ & $402.3 \pm 147.2$ & .361 \\
\hline Annuloplasty GEARS score, mean $\pm \mathrm{SD}$ & $8.2 \pm 1.8$ & $7.8 \pm 1.8$ & $7.8 \pm 1.9$ & $7.5 \pm 2.4$ & .178 \\
\hline
\end{tabular}

$S D$, Standard deviation; ITA, internal thoracic artery; GEARS, global evaluative assessment of robotic skills.

the first 10 trainees to complete the initial assessments were used to calculate a minimum sample size of 8 participants in each treatment arm to detect a clinical significance with a statistical power of 0.90 . Because a second expert surgeon was required to set levels of proficiency for each task, we felt that expanding enrollment to 10 participants for each arm would account for any increased variability, without being too large for the unavoidable logistical and financial constraints surrounding the study design.

Data analysis was based on the original random allocation of each participant into each training stream to which he or she was assigned without any crossover. All continuous variables were compared using Kruskal-Wallis analysis of variance, which accounts for our small sample sizes and does not assume normality of the data. The continuous variables from each group were then compared with the experts individually, using the Mann-Whitney $U$ test.

\section{RESULTS \\ Baseline Demographics}

At baseline, participants in all 4 training streams were similar in terms of age, sex, year of training, and previous robotic experience. In addition, no difference was detected in each group's performance of the ITA dissection and mitral valve annuloplasty for both the time-based scoring and the GEARS assessment (Table 1). The expert surgeons scored significantly higher than the trainees in the original assessment time-based scores for the 10-cm ITA dissection and the mitral valve annuloplasty tasks, as well as significantly better on the average GEARS score (Table 1).

\section{Wet Lab}

Trainees in the wet lab improved their mean 10-cm ITA dissection time-based score from $488.8 \pm 228.6$ on the initial assessment to $1076.1 \pm 25.8$ at the final assessment. Similarly, they improved their mean time-based mitral valve annulopasty score from $381.1 \pm 107.8$ at the initial assessment to $602.2 \pm 11.4$ at the final assessment. Both of these scores were significantly better than those of the experts at the final assessment $(P=.003$ and .031 , respectively) (Figure 3 ). The wet lab trainees also improved their average GEARS score from $9.3 \pm 1.7$ to $24.9 \pm 2.6$ at the final assessment, which was not significantly different from the score of the experts $(P=.704)$ (Figure 4). The average total training time to reach the level of proficiency set by our experts was $116.5 \pm 32.1$ minutes for trainees in the wet lab group, with an average duration of training of $25.9 \pm 13.5$ days between the initial and final assessments (Figure 5).

\section{Dry Lab}

Trainees in the dry lab improved their mean 10-cm ITA dissection time-based score from $388.9 \pm 295.1$ at the initial assessment to $859.0 \pm 143.2$ at the final assessment, with no statistical difference between their scores and the experts' score for this task $(P=.191)$. Trainees also improved their mean time-based mitral valve annulopasty score from $304.9 \pm 197.0$ at the initial assessment to $523.6 \pm 48.9(P=.013)$ at the final assessment, which despite the improvement was significantly lower than the experts' average score $(P=.013)$ (Figure 3$)$. The dry lab trainees also improved their average GEARS score from $8.6 \pm 3.3$ to $22.5 \pm 3.7$ at the final assessment, which was not significantly different from the experts' score $(P=.160)$ (Figure 4). The average total training time to reach the level of proficiency set by our experts was $98.0 \pm 52.2$ minutes for the dry lab trainees, with an average duration of training of $34.0 \pm 32.9$ days between the initial and final assessments (Figure 5).

\section{Virtual Reality}

Trainees in the virtual reality lab improved their mean 10-cm ITA dissection time-based score from $457.6 \pm 259.9$ at the initial assessment to $957.3 \pm 98.9$ at the final assessment. Similarly, they improved their mean time-based mitral valve annulopasty score from $409.5 \pm 106.1$ at the initial assessment to $580.4 \pm 14.4$ at the final assessment. There was no significant difference in either of these scores between the trainees and experts at the final assessment ( $P=.624$ and .967 , respectively) (Figure 3). The virtual reality trainees also improved their average GEARS score from $10.2 \pm 3.0$ to $22.8 \pm 2.7$ at 

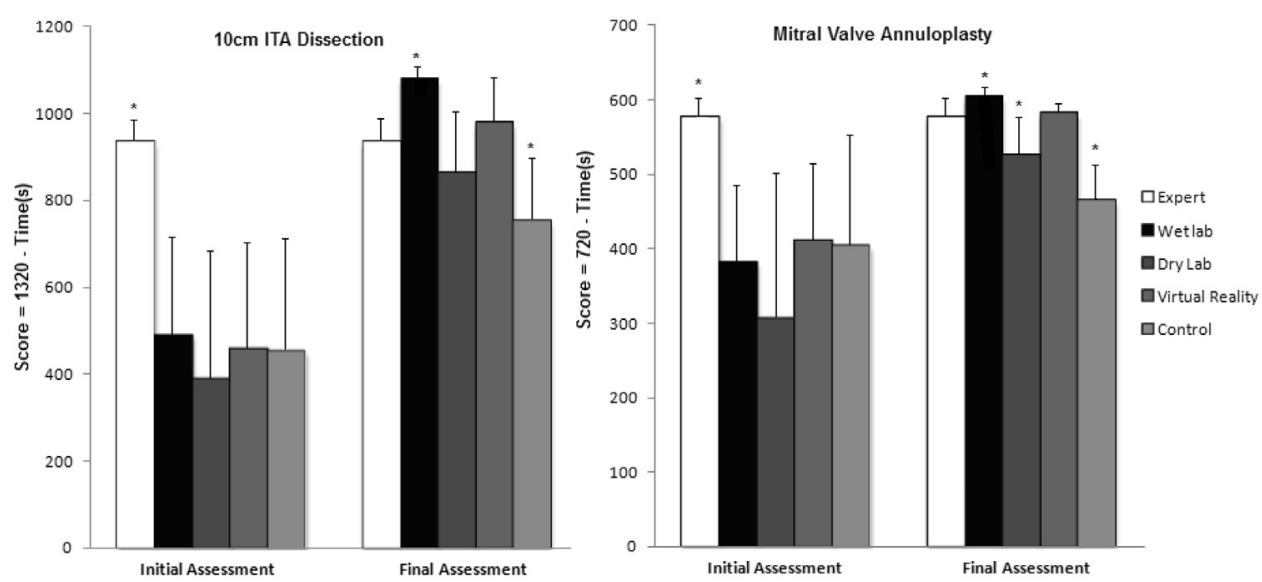

\begin{tabular}{|c|c|c|c|c|}
\hline & Wet Lab $(n=10)$ & $\begin{array}{c}\text { Dry Lab } \\
(\mathrm{n}=10)\end{array}$ & $\begin{array}{c}\text { Virtual Reality } \\
(n=10)\end{array}$ & Control $(n=10)$ \\
\hline $\begin{array}{l}\text { Initial } 10 \mathrm{~cm} \text { ITA Dissection, } \\
\text { Score } \pm \text { SD }\end{array}$ & $488.8 \pm 228.6$ & $388.9 \pm 295.1$ & $457.6 \pm 259.9$ & $451.0 \pm 264.1$ \\
\hline $\begin{array}{l}\text { Final } 10 \mathrm{~cm} \text { ITA Dissection, } \\
\text { Score } \pm \text { SD, p value }\end{array}$ & $\begin{array}{c}1076.1 \pm 25.8 \\
0.003\end{array}$ & $\begin{array}{c}859.0 \pm 143.2 \\
0.191\end{array}$ & $\begin{array}{c}957.3 \pm 98.9 \\
0.624\end{array}$ & $749.1 \pm 171.90 .008$ \\
\hline $\begin{array}{l}\text { Initial Mitral Annuloplasty, } \\
\text { Score } \pm \text { SD }\end{array}$ & $381.1 \pm 107.8$ & $304.9 \pm 197.0$ & $409.5 \pm 106.1$ & $402.3 \pm 147.2$ \\
\hline $\begin{array}{l}\text { Final Mitral Annuloplasty, } \\
\text { Score } \pm \text { SD, p value }\end{array}$ & $602.2 \pm 11.40 .031$ & $\begin{array}{c}523.6 \pm 48.9 \\
0.013\end{array}$ & $\begin{array}{c}580.4 \pm 14.4 \\
0.967\end{array}$ & $463.8 \pm 86.40 .001$ \\
\hline
\end{tabular}

FIGURE 3. Time-based scores for $10-\mathrm{cm}$ ITA dissection and mitral annuloplasty. $* P<.05$. ITA, Internal thoracic artery; $S D$, standard deviation.

the final assessment, which was not significantly different from the experts' score $(P=.110)$ (Figure 4). The average total training time to reach the level of proficiency set by our experts was $560.5 \pm 167.4$ minutes for trainees in the virtual reality group, with an average duration of training of $46.7 \pm 21.3$ days between the initial and final assessments (Figure 5).

\section{Controls}

Trainees in the control group showed an improvement in their mean $10 \mathrm{~cm}$ ITA dissection time-based score from

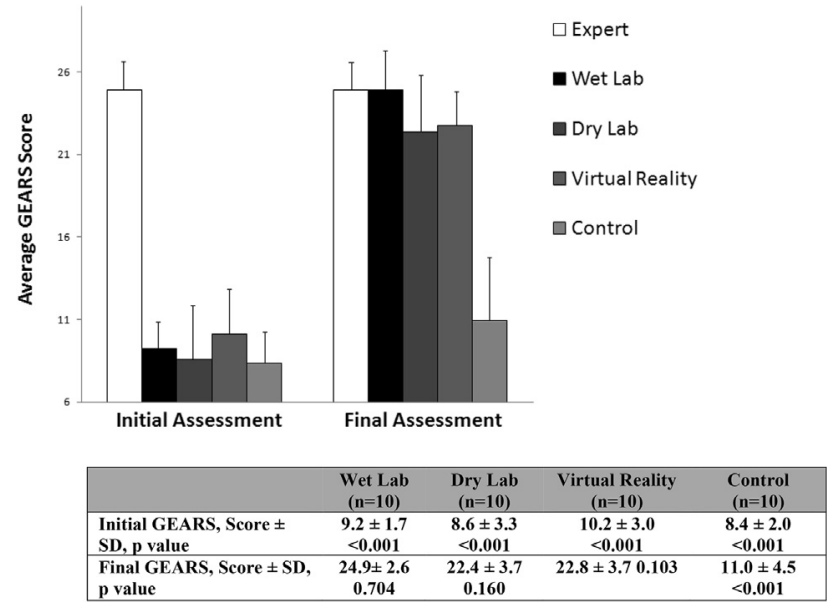

FIGURE 4. Average GEARS scores. GEARS, Global evaluative assessment of robotic skills; $S D$, standard deviation.
$451.0 \pm 264.1$ at the initial assessment to $749.1 \pm 171.9$ at the final assessment. A similar mild improvement was seen in their mean time-based mitral valve annulopasty score, from $402.3 \pm 147.2$ at the initial assessment to $463.8 \pm 86.4$ at the final assessment. With only these small improvements, both time-based scores were significantly lower than those of the experts at the final assessment $(P=.008$ and .001 , respectively) (Figure 3$)$. The trainees in the control group showed very limited improvement in their average GEARS score, from $8.4 \pm 2.0$ to $11.0 \pm 4.5$ at the final assessment, which was significantly different from the experts' score $(P<.001)$ (Figure 4$)$. The average interval between the initial and final assessments was $34.6 \pm 24.1$ days (Figure 5).

\section{DISCUSSION}

The failure to detect any statistical difference between the training groups' demographics and baseline scores indicates that our randomization was appropriate, and that no group was at an advantage at the commencement of robotic training.

\section{Wet Lab}

The primary outcome scores for the wet lab indicate the strength of this simulation modality, because this group outperformed all others for all tasks and even performed significantly better than our experts. This demonstrates how an exercise that is most similar to the actual operative experience yields the most efficient method of training. This 


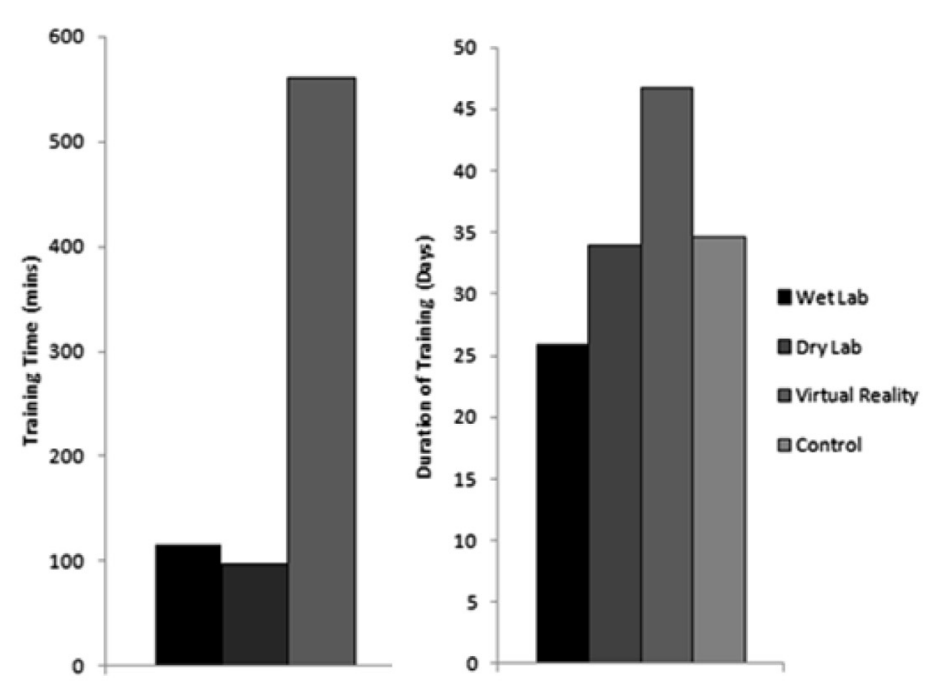

\begin{tabular}{|lccccc|}
\hline & $\begin{array}{c}\text { Wet Lab } \\
(\mathrm{n}=10)\end{array}$ & $\begin{array}{c}\text { Dry Lab } \\
(\mathrm{n}=10)\end{array}$ & $\begin{array}{c}\text { Virtual } \\
\text { Reality } \\
(\mathrm{n}=10)\end{array}$ & $\begin{array}{c}\text { Control } \\
(\mathrm{n}=10)\end{array}$ & p value \\
\hline $\begin{array}{l}\text { Total Training } \\
\text { Time, mins } \pm \text { SD }\end{array}$ & $\mathbf{1 1 6 . 5} \pm \mathbf{3 2 . 1}$ & $\mathbf{9 8 . 0} \pm \mathbf{5 2 . 2}$ & $\mathbf{5 6 0 . 5} \pm 167.4$ & - & $<0.001$ \\
$\begin{array}{l}\text { Duration of } \\
\text { Training, days } \pm \text { SD }\end{array}$ & $\mathbf{2 5 . 9} \pm 13.5$ & $\mathbf{3 4 . 0} \pm \mathbf{3 2 . 9}$ & $46.7 \pm 21.3$ & $\mathbf{3 4 . 6} \pm \mathbf{2 4 . 1}$ & $\mathbf{0 . 1 1 6}$ \\
\hline
\end{tabular}

FIGURE 5. Average total training time and duration of training. $S D$, Standard deviation.

concept has been alluded to previously, and multiple examples exist in which educators have attempted to increase the fidelity of simulation to create a more realistic and effective training model (eg, infusion of pulsatile blood into animal/cadaveric tissues) ${ }^{12}$; however, this is the first study to demonstrate this principle through experimentation. Exposure to these high-fidelity models allowed trainees to become familiar with the relevant anatomy and robotic instrumentation, delineated the procedural steps, and provided the repetition necessary to develop a safe and efficient technique. However, high costs, difficult acquisition/storage/preparation/disposal of tissues, and the need for an expert presence are major barriers to implementing this type of a training program, consistent with the conclusions of other authors in the simulation literature. ${ }^{11,12}$ Because of this, the wet lab is best suited for training individuals who have already obtained basic robotic skills through other modalities, so that these sessions can be used to focus on precise anatomic dissection and advanced procedurally specific techniques.

\section{Dry Lab}

The dry lab group improved all scores at the final assessments but were unable to reach the level of proficiency set by our experts for the mitral annuloplasty. Although they did reach the level of proficiency for the ITA dissection, their average scores were consistently the lowest of the training streams. This indicates that the exposure to only simple tasks does not translate to more complex procedures as well as the other training modalities. Robotic training programs looking to incorporate dry lab simulation also must account for the availability of a designated training robot, as well as the high costs of disposable robotic instruments.

\section{Virtual Reality}

The virtual reality group improved their scores and met the levels of proficiency set by our experts for the timebased and GEARS scores. Although they did not achieve the same scores as the wet lab group, this method of training certainly allows for the acquisition of robotic skill. The merits of virtual reality are demonstrated by the fact that these individuals were never exposed to the porcine tissues or the technique involved in either of the assessments for the entire duration of their training. Their improvements in performance came from an understanding of the robot's functions as a competent technician of the system. The major advantage of this type of training is the powerful scoring tool that provides ongoing feedback for the trainees to improve robotic proficiency by monitoring a variety of different metrics (eg, distance traveled, excessive force). This gives the trainee a better idea of areas for improvement, other than simply performing it faster, which is the only insight gained from time-based scoring systems. The multiple recorded metrics required to pass each task explains the significantly longer training times needed for subjects in the virtual reality group. 


\section{Controls}

The control group showed minor improvements on their final assessments, but without any extra exposure to the robot, they were unable to meet the expert level of proficiency for any of the primary objectives. These improvements likely represent some familiarization with the surgical anatomy and robotic technique after completing the initial assessment. Because the control group failed to reach all levels of proficiency, it is reasonable to assume that the improvements seen in the 3 training groups was due to the experience and skill that they gained during the training exercises of this study.

\section{GEARS Scoring Tool}

The GEARS scoring tool proved to be a better indicator of overall robotic proficiency compared with the time-based scoring systems. It is not specific to any particular robotic surgical procedure, but does account for the overall efficiency of robotic surgery, which is a reflection of time. In addition to this GEARS focuses on depth perception, bimanual dexterity, force sensitivity, autonomy, and robotic control, making it a far more robust evaluation tool than time-based scoring systems. The GEARS scoring tool has been shown to objectively detect differences between novice operators of the robot and expert staff surgeons. ${ }^{22}$ This is consistent with what has been demonstrated in this study based on the baseline assessment scores. The inability to detect a significant difference in the 3 training streams' scores with the experts at the final assessments demonstrates their significant improvement in robotic surgical abilities.

This work is the first prospective randomized controlled trial to ever compare the currently available simulation modalities used in robotic surgical training, and is one of the largest studies regarding robotic training completed to date. We report a $96.25 \%$ completion rate for the final assessment. All individuals completed the training and assessments except for 1 trainee who did not complete the ITA assessment before completing his training at our institution and another who was unable to complete the training after randomization owing to clinical responsibilities.

\section{Study Limitations}

One limitation of this study is the small sample size, which is consistent with many similar publications with sample sizes as low as 2 and nonsurgical participants owing to the time constraints of surgical trainees. ${ }^{11}$ However, all proper power calculations were carried out to ensure the statistical validity of the results. Furthermore, the cost and limited availability of porcine materials precluded the study from involving more extensive surgical skills. With respect to the ITA dissection, only a 10-cm length of the ITA was harvested, to conserve materials. This proved to be an adequate compromise, allowing evaluation of robotic proficiency but in a simpler task than dissection of the entire 20 - to $30-\mathrm{cm}$-long ITA pedicle. Finally, only 1 investigator evaluated each robotic assessment, possibly serving as a potential source of bias. Although the GEARS scoring tool has been shown to have excellent internal consistency with low variability among evaluators, ${ }^{22}$ this was done purposefully to ensure an absence of interevaluator variability with all recordings deidentified and coded, blinding the investigator to the type of participant (expert/trainee) and the stage of assessment (baseline/final).

\section{CONCLUSIONS}

Simulation-based exercises should be incorporated into training programs to keep up with advancements in robotic technology and allow for a higher-yield training experience during each robotic operation. Training programs must evaluate their own institutional resources to determine the optimal simulation training that they can offer. If a center has the appropriate resources, then the results of this study highly favor the high-fidelity wet lab simulation, under the guidance of an expert robotic surgeon, for the fastest acquisition of expert-level robotic skill. However, if this is not possible, then virtual reality simulation offers a reasonable alternative that allows for familiarization with the robot's instrumentation and proficiency with a variety of robotic skills.

As robotics enters the mainstream of cardiac surgery, the need for a reliable robotic training program will become paramount. This work will serve to guide training programs in investing resources in cost-effective, high-yield simulation exercises to improve the training of new robotic cardiac surgeons.

\section{Conflict of Interest Statement}

Authors have nothing to disclose with regard to commercial support.

\section{References}

1. Chitwood WR Jr, ed. Atlas of Robotic Cardiac Surgery. London: Springer; 2014: $1-10$.

2. Gao C, ed. Robotic Cardiac Surgery. Dordrecht: Springer; 2014:1-15.

3. Pugin F, Bucher P, Morel P. History of robotic surgery: from AESOP and ZEUS to da Vinci. J Visc Surg. 2011;148(5 Suppl):e3-8.

4. Poston RS, Tran R, Collins M, Reynolds M, Connerney I, Reicher B, et al. Comparison of economic and patient outcomes with minimally invasive versus traditional off-pump coronary artery bypass grafting techniques. Ann Surg. 2008;248:638-46.

5. Moss E, Murphy D, Halkos M. Robotic cardiac surgery: current status and future directions. Robot Surg Res Rev. 2014;1:27-36.

6. Kaneko T, Chitwood WR Jr. Current readings: status of robotic cardiac surgery. Semin Thorac Cardiovasc Surg. 2013;25:165-70.

7. Chitwood WR Jr, Nifong LW, Chapman WH, Felger JE, Bailey BM, Ballint T, et al. Robotic surgical training at an academic institution. Ann Surg. 2001;234: 475-84.

8. Whitehurst SV, Lockrow EG, Lendvay TS, Propst AM, Dunlow SG, Rosemeyer CJ, et al. Comparison of two simulation systems to support robotic-assisted surgical training: a pilot study (Swine model). J Minim Invasive Gynecol. 2015;22:483-8. 
9. Ganpule A, Chhabra JS, Desai M. Chicken and porcine models for training in laparoscopy and robotics. Curr Opin Urol. 2015;25:158-62.

10. Schachner T, Bonaros N, Wiedemann D, Weidinger F, Feuchtner G, Friedrich G, et al. Training surgeons to perform robotically assisted totally endoscopic coronary surgery. Ann Thorac Surg. 2009;88:523-7.

11. Schreuder HW, Wolswijk R, Zweemer RP, Schijven MP, Verheijen RH. Training and learning robotic surgery, time for a more structured approach: a systematic review. Br J Obstet Gynaecol. 2012;119:137-49.

12. Liss MA, McDougall EM. Robotic surgical simulation. Cancer J. 2013;19:124-9.

13. Kumar A, Smith R, Patel VR. Current status of robotic simulators in acquisition of robotic surgical skills. Curr Opin Urol. 2015;25:168-74.

14. Fisher RA, Dasgupta P, Mottrie A, Volpe A, Khan MS, Challacombe B, et al. An over-view of robot assisted surgery curricula and the status of their validation. Int J Surg. 2015;13:115-23.

15. Mimic Technologies Inc. Appendix B: experienced surgeon data. Overview of experience surgeon data. 2012;217-42.

16. Finnegan KT, Meraney AM, Staff I, Schichman SJ. da Vinci skills simulator construct validation study: correlation of prior robotic experience with overall score and time score simulator performance. Urology. 2012;80:330-5.
17. Kelly DC, Margules AC, Kundavaram CR, Narins H, Gomella LG, Trabulsi EJ, et al. Face, content, and construct validation of the da Vinci Skills Simulator Urology. 2012;79:1068-72.

18. Ben-Or S, Nifong LW, Chitwood WR Jr. Robotic surgical training. Cancer J. 2013;19:120-3.

19. Liu M, Curet M. A review of training research and virtual reality simulators for the da Vinci surgical system. Teach Learn Med. 2015;27:12-26.

20. Rajanbabu A, Drudi L, Lau S, Press JZ, Gotlieb WH. Virtual reality surgical simulators-a prerequisite for robotic surgery. Indian J Surg Oncol. 2014:5:125-7.

21. Ritter EM, Scott DJ. Design of a proficiency-based skills training curriculum for the fundamentals of laparoscopic surgery. Surg Innov. 2007;14:107-12.

22. Goh AC, Goldfarb DW, Sander JC, Miles BJ, Dunkin BJ. Global evaluative assessment of robotic skills: validation of a clinical assessment tool to measure robotic surgical skills. J Urol. 2012;187:247-52.

Key Words: robotic cardiac surgery, simulation training, randomized controlled trial, wet lab, dry lab, virtual reality

Readers who found these articles interesting may also like to read the following papers found in recent and future issues of our sister publications, Seminars in Thoracic and Cardiovascular Surgery and Operative Techniques in Thoracic and Cardiovascular Surgery!

\section{Education}

News and Views: STS Adult Cardiac Surgery Database: The Driving Force for Improvement in Cardiac Surgery. AL Shroyer. Semin Thorac Cardiovasc Surg 2015; Summer; 27(2):144-151.

Special Issue: The History of Heart Surgery at Johns Hopkins Hospital. Nishant D Patel. Semin Thorac Cardiovasc Surg 2015; Winter; 27(4):341-352.

Special Issue: Mayo Clinic: An Institutional History of General Thoracic Surgery. Erin A Gillespie. Semin Thorac Cardiovasc Surg 2015; Winter; 27(4):353-359.

Special Issue: The History of Duke Thoracic Surgery. Peter K Smith. Semin Thorac Cardiovasc Surg 2015; Winter; $27(4): 360-369$.

Special Issue: History and Current Status of Cardiovascular Surgery at the University of Pennsylvania. Michael A Acker. Semin Thorac Cardiovasc Surg 2015; Winter; 27(4):370-373.

Special Issue: Doctors of Thoracic Surgery: The Division of Thoracic Surgery at Toronto General Hospital. Shaf Keshavjee. Semin Thorac Cardiovasc Surg 2015; Winter; 27(4):374-379.

Special Issue: Evolution of the Pediatric and Congenital Heart Surgery Service at Texas Children's Hospital: 1954-2015. Charles D Fraser, Jr. Semin Thorac Cardiovasc Surg 2015;Winter; 27(4):380-387.

Special Issue: One Hundred Years of History at Stanford University: Thoracic and Cardiovascular Surgery. Y Joseph Woo. Semin Thorac Cardiovasc Surg 2015; Winter: 27(4):388-397.

Special Issue: History of Cardiac Surgery at the Peter Bent Brigham and Brigham and Women's Hospital, Boston, Massachusetts. Lawrence H Cohn. Semin Thorac Cardiovasc Surg 2015; Winter; 27(4):398-402.

Special Issue: The Thoracic Surgery Service at Memorial Sloan Kettering Cancer Center. Valerie W Rusch. Semin Thorac Cardiovasc Surg 2015; Winter; 27(4):403-409.

Special Issue: Development of Congenital Cardiac Surgery in Toronto. William G Williams. Semin Thorac Cardiovasc Surg 2015; Winter; 27(4):410-415. 
APPENDIX 1. Dry lab task 1: camera movement and clutching template

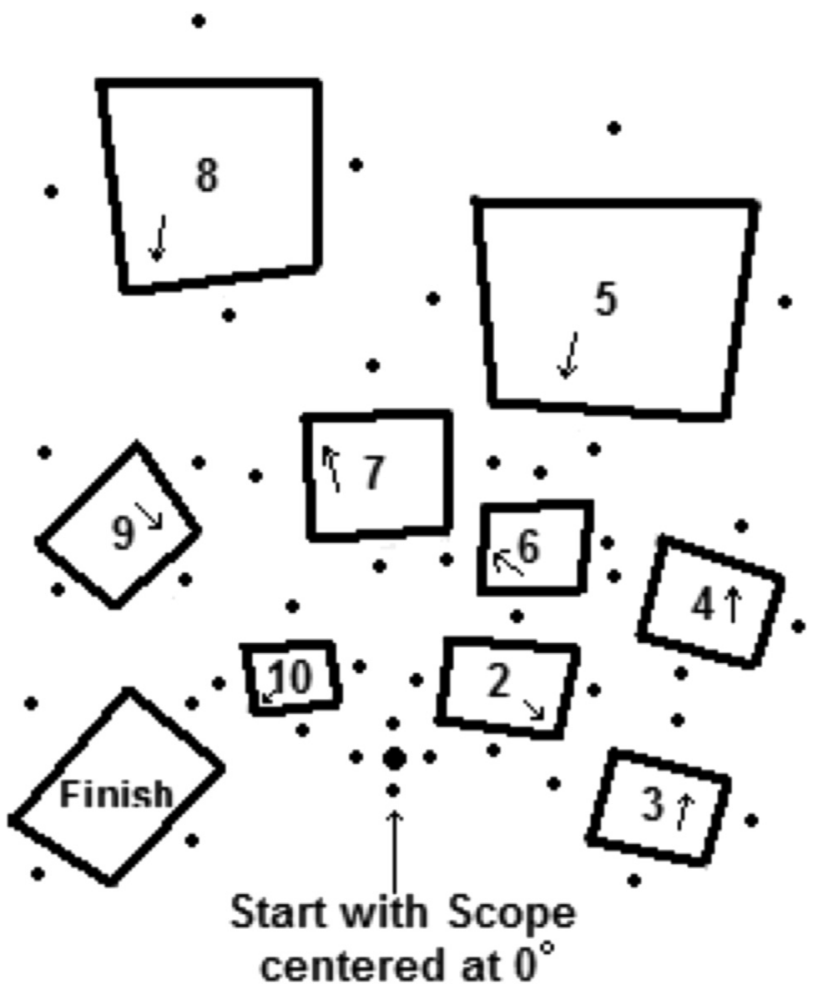

APPENDIX 2. Wet and dry lab time-based scoring equations

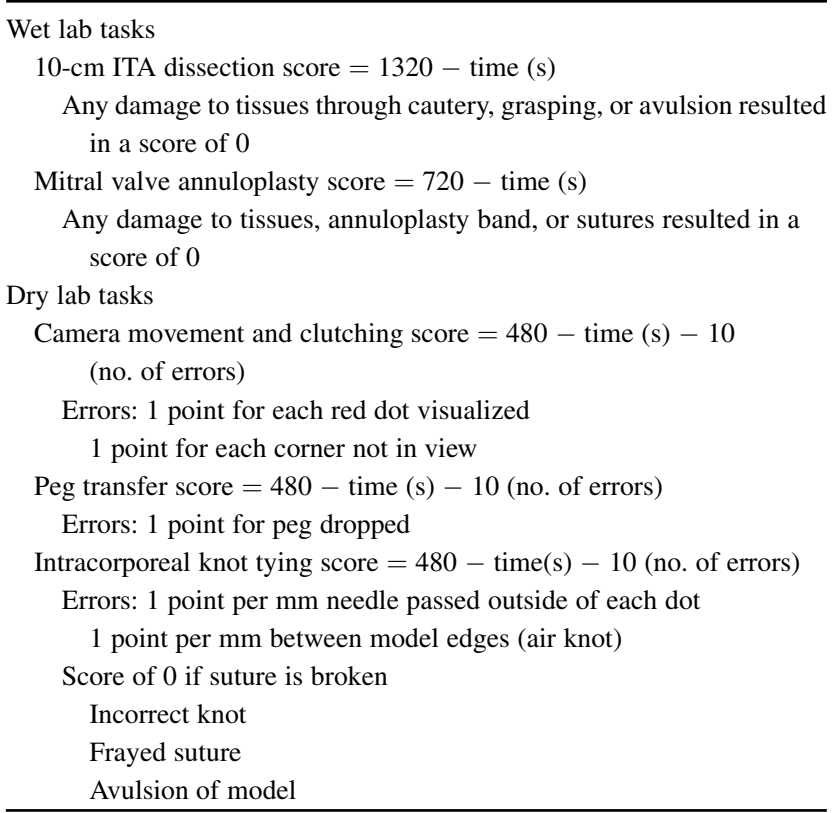

This scoring system was developed from the FLS training program and was replicated as closely as possible and adapted for the robot. The FLS program set levels of proficiency for these tasks by having 2 fellowship-trained advanced laparoscopic surgeons, whose practices consisted of mainly minimally invasive surgery but who were not overly familiar with the FLS tasks before initiation of the study, complete each task 5 times. It was decided a priori that these values would be pooled, and any outlier more than 2 SD from the mean would be excluded (there were none). The time for proficiency of these tasks was then set as the mean time to completion from this dataset. This process was repeated for the tasks listed above by 2 expert robotic surgeons, again 5 times, and the times were pooled to determine the overall proficiency score. In this system, the proficiency score equation is as follows:

$$
\text { Score }=\text { Max time }- \text { Expert pooled time }- \text { Errors. }
$$

Here max time is the total time that an individual was allowed to complete the task. This time was usually 2 to 3 times greater than the expert pooled time, to allow participants as much time as necessary to complete the task, and also a point where any more time required would represent such an inefficient performance that a score of 0 would be appropriate. Expert pooled time is the mean time for completion of each expert's five attempts. Errors were defined a priori, and included the defined errors of the FLS program that were still appropriate for the robotic tasks. ITA, Internal thoracic artery. 
APPENDIX 3. Western protocol for virtual reality training

\section{Virtual reality}

simulation exercise/level

Camera targeting/2

Energy switching/2

Pegboard/2

Matchboard/2

Ring walk/3

Matchboard/3

Energy dissection/2

Suture sponge/3

Vertical defect suturing

\section{Description}

Trainees grasp small objects and transfer them though a series of platforms and baskets while zooming in and out to focus the camera on specific targets.

Trainees use the pedals to cauterize vessels and tissue with both monopolar and bipolar cautery.

Trainees remove several rings from pegs on a board and transfer them between hands to place them on specific pegs on the ground.

Trainees must pick up letters and numbers that are scattered around a box with 3 lids. Each lid covers a spot where the correct number or letter must be placed without touching the sides.

Trainees must move a ring through a rope covered by obstacles, requiring transferring between both hands and a third arm for restraction.

Trainees use the same matchboard as before, but a second sliding door covers each box, necessitating the use of a third hand for retraction to place each number or letter inside.

Trainees are required to use bipolar cuatery and scissors to cauterize and cut 6 small branching arteries off of a larger artery.

Trainees are given a needle that they must pass back and forth between instruments and suture through targets on a sponge brick, forcing them to take forward and backhand bites with both hands.

Trainees place a simple interrupted suture and place 3 square knots on 2 vertical defects.
Primary skill tested

Camera control

Energy control

Endowrist manipulation

Endowrist manipulation

Fourth arm control

Fourth arm control

Energy control

Needle driving, advanced

Needle driving, advanced

APPENDIX 4. Global evaluative assessment of robotic skill (GEARS) scoring tool

Depth perception

\begin{tabular}{lccc}
\hline 1 & 2 & 3 & 4 \\
\hline $\begin{array}{l}\text { Constantly overshoots target, } \\
\text { wide swings, slow to correct } \\
\text { Bimanual dexterity }\end{array}$ & $\begin{array}{c}\text { Some overshooting or missing } \\
\text { target, but quick to correct }\end{array}$ & $\begin{array}{c}\text { Accurately directs instruments in the } \\
\text { correct plane to target }\end{array}$
\end{tabular}

Bimanual dexterity

\begin{tabular}{|c|c|c|c|c|}
\hline 1 & 2 & 3 & 4 & 5 \\
\hline $\begin{array}{l}\text { Uses only one hand, ignores } \\
\text { nondominant hand, } \\
\text { poor and coordination }\end{array}$ & & $\begin{array}{l}\text { Uses both hands, but does no } \\
\text { optimize interaction between } \\
\text { hands }\end{array}$ & & $\begin{array}{l}\text { Expertly uses both hands in a } \\
\text { complementary way to provide } \\
\text { best exposure }\end{array}$ \\
\hline
\end{tabular}

Efficiency

\begin{tabular}{|c|c|c|c|}
\hline 1 & 2 & 4 & 5 \\
\hline $\begin{array}{l}\text { Inefficienct efforts; many uncertain } \\
\text { movements, constantly changing } \\
\text { focus or persisting without progress }\end{array}$ & $\begin{array}{l}\text { Slow, but planned movements are } \\
\text { reasonably organized }\end{array}$ & & $\begin{array}{l}\text { Confident, efficient and safe conduct, } \\
\text { maintains focus on task, fluid } \\
\text { progression }\end{array}$ \\
\hline
\end{tabular}

Force sensitivity

\begin{tabular}{|c|c|c|c|c|}
\hline 1 & 2 & 3 & 4 & 5 \\
\hline $\begin{array}{l}\text { Rough moves, tears tissue, injures nearby } \\
\text { structures, poor control, frequent suture } \\
\text { breakage }\end{array}$ & & $\begin{array}{l}\text { Handles tissues reasonably well, } \\
\text { minor trauma to adjacent tissue, } \\
\text { rare suture breakage }\end{array}$ & & $\begin{array}{l}\text { Applies appropriate tension, negligible } \\
\text { injury to adjacent structures, no } \\
\text { suture breakage }\end{array}$ \\
\hline
\end{tabular}

Autonomy

$1 \quad 2 \quad 3 \quad 4$

Unable to complete entire task, even with verbal guidance

Able to complete task safely with moderate guidance

4

Able to complete task independently without prompting

Robotic control

1

Consistently does not optimize view, hand position, or repeated collisions even with guidance
2

$$
3
$$

View is sometime not optimal. Occasionally needs to relocate arms. Occasional collisions and obstruction of assistant. 